\title{
A Study on Rotary Friction Welding of Titanium Alloy (Ti6Al4V)
}

\author{
Ho Thi My Nu $\mathbb{D}^{1,2}$ Truyen The Le, ${ }^{1}$ Luu Phuong Minh, ${ }^{2}$ and Nguyen Huu Loc ${ }^{2}$ \\ ${ }^{1}$ Ho Chi Minh City University of Food Industry, 140 Le Trong Tan Street, Ho Chi Minh City 760310, Vietnam \\ ${ }^{2}$ Ho Chi Minh City University of Technology-VNUHCM, 268 Ly Thuong Kiet Street, Ho Chi Minh City 740400, Vietnam \\ Correspondence should be addressed to Ho Thi My Nu; 8140019@hcmut.edu.vn
}

Received 24 October 2018; Revised 9 January 2019; Accepted 4 February 2019; Published 10 March 2019

Academic Editor: Stanislaw Dymek

Copyright ( $\odot 2019$ Ho Thi My Nu et al. This is an open access article distributed under the Creative Commons Attribution License, which permits unrestricted use, distribution, and reproduction in any medium, provided the original work is properly cited.

\begin{abstract}
The selection of high-strength titanium alloys has an important role in increasing the performance of aerospace structures. Fabricated structures have a specific role in reducing the cost of these structures. However, conventional fusion welding of highstrength titanium alloys is generally conducive to poor mechanical properties. Friction welding is a potential method for intensifying the mechanical properties of suitable geometry components. In this paper, the rotary friction welding (RFW) method is used to study the feasibility of producing similar metal joints of high-strength titanium alloys. To predict the upset and temperature and identify the safe and suitable range of parameters, a thermomechanical model was developed. The upset predicted by the finite element simulations was compared with the upset obtained by the experimental results. The numerical results are consistent with the experimental results. Particularly, high upset rates due to generated power density and forging pressure overload that occurred during the welding process were investigated. The performances of the welded joints are evaluated by conducting microstructure studies and Vickers hardness at the joints. The titanium rotary friction welds achieve a higher tensile strength than the base material.
\end{abstract}

\section{Introduction}

Titanium alloy (Ti6Al4V) is a lightweight, durable material that is extensively employed in the airplane and aerospace industries. Ti6A14V is also important in other fields of production, such as car components, medical instruments, and leisure industries [1]. Especially, Ti6A14V is used in highly stressed gas turbine components such as the disk and spacer assembly. Previously, one-piece closed die forgings have been used to machine these components; however, this technique causes considerable machining and raw material waste. Inertia welding of three separate sections, such as a flat pancake forging and two rolled rings, was expected to provide a potential cost reduction. The use of weldments for this type of component offers design options for other structures that cannot be feasibly constructed from one piece. However, choosing suitable joining techniques is key to the successful application of an alloy in many important areas. Friction welding is chosen for joining titanium alloys due to its many advantageous features, such as low energy consumption, high productivity, and it does not produce smoke and welding dust, does not need fill material, and does not need an external heat source, compared with other welding methods $[2,3]$.

Two cylindrical titanium alloy components can be welded by the frictional heat that is generated, as shown in Figure 1. In the rotary friction welding process, workpieces are combined under load; one part is revolved against the other part, which causes frictional heat to develop at the interface surface. When the joint area is sufficiently plastic as a result of an increase in temperature, the rotation is stopped and the end force is increased to forge and consolidate the joint. The process is considered to be solid state welding as the temperature in the welding process is lower than the melting point of the material. During friction welding, the temperature, stress, and deformation vary depending on the parameters of the process. Understanding the relationship among these parameters will help determine the optimal parameters of the process and methods to improve the design quality and manufacture of friction welding products. The effect of forging pressure is to promote the mixing of two materials, which consolidates the weld. The basic parameters 


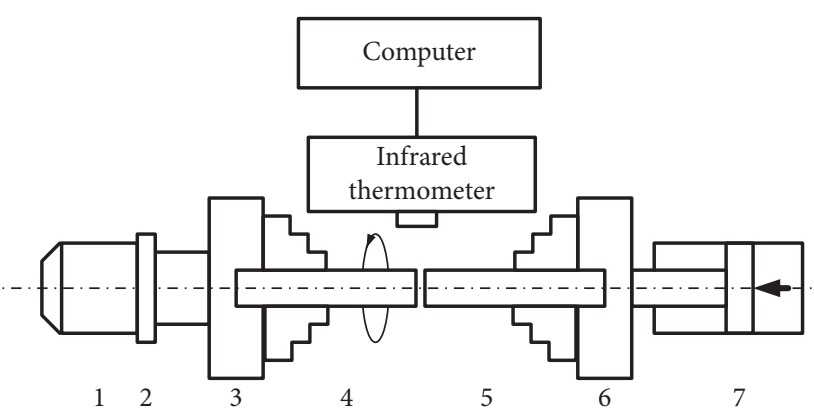

(1) Motor

(2) Brake

(3) Rotating chuck

(4) Rotating workpiece

(5) Nonrotating workpiece

(6) Nonrotating chuck

(7) Hydraulic cylinder

FIGURE 1: Schema of experimental setup rotary friction welding.

of the friction welding process are the friction pressure, friction time, rotational speed, and forging pressure.

Many studies of rotary friction welding for various materials, such as stainless steel ANSI 304, aluminium alloys, carbon steels, and copper alloys, have been published for many years [4]. However, a few studies have reported the rotary friction welding of titanium alloys. Previous research has shown that titanium alloys can be welded by linear methods with an excellent crystal structure of the joint weld. Linear friction welding (LFW) is an established technology for the manufacture of titanium alloy-integrated bladed disks for aeroengines [5-8]. Dalgaard [9] reported that an increase in the relative motion between two pieces increases the heat density, which decreases the friction coefficient and generates a low heating rate.

Rotary friction welding of Ti6Al4V has been extensively performed using different parameters or process conditions. The variation in the process parameters has a significant influence on the properties of friction welded Ti6Al4V. Poor selection of process parameters produces a weld joint with poor mechanical properties. Avinash et al. [10] investigated the feasibility of producing similar metal joints of this titanium alloy by the rotary friction welding method. The joints are produced at three different speeds, and the performances of the welded joints are evaluated by conducting microstructure studies and Vickers hardness and tensile tests at the joints. The produced weld joints are sound, and the ductile fractures in the tensile weld specimens occur at locations far from the welded joints.

The research also reported that the heat density is inversely proportional to the axial friction pressure. Palanivel et al. [11] reported lower coefficients of friction at higher rotational speeds, which produce longer heating times, high heat conductivity rates, and a specific amount of material pushed out in a form of flash. Although other researchers believed that the variation in the process parameters have a significant influence on the weld joint properties, Yates [12] believed that the rotational speed is the least sensible process parameter and axial pressure does not have a significant effect if it is not varied over an extensive range.

In friction welding, the problem that a person usually encounters is how to experimentally measure the temperature variation from the centre to the periphery and the stress developed during the process. However, this problem is difficult to investigate with experiments due to the complexity of thermal mechanics, such as the changes in the thermal properties of a material as the temperature changes and the mechanical properties of the material change as the deformation increases. This complexity hinders the installation of a direct temperature gauge on the solder parts. Costly materials, such as titanium, should be limited to testing to reduce costs. Thus, numerical simulation with modern computational tools will solve the challenges of friction welding with titanium alloys. Therefore, modelling techniques are employed to understand the physical phenomena. A thermodynamic model is employed based on the Johnson-Cook material model. The upset predicted by the finite element simulations were compared with the upset obtained by the experimental results.

\section{Numerical Modelling}

Abaqus/Standard software is employed to simulate the heat transfer and deformation of solder elements during rotary friction welding. Due to axial symmetry, a $2 \mathrm{D}$ model is used to reduce the computational time. The $2 \mathrm{D}$ model runtime is a few hours versus a few days when using $3 \mathrm{D}$ modelling. The specimen has a width of $18 \mathrm{~mm}$ and a length of $40 \mathrm{~mm}$, as shown in Figure 2. The left part is fixed while the right part rotates about the axis. In this model, the meshing was conducted using a 4-node quad element with coupled displacement and temperature, reduced integration, and hourglass control. The number of elements in the model is 104288 .

Temperature-dependent physical properties and mechanical properties, as well as a viscoplastic constitutive equation, were applied in the model. The thermal and mechanical responses to the material during the friction welding process were investigated by finite element simulations. In this paper, a coupled thermomechanical model was developed for analysis.

In order to avoid high mesh distortion, this study use Arbitrary Lagrangian Eulerian (ALE) modelling technique to simulate RFW process. The ALE element formulation is a standard numerical approach for solving large strain deformation problems encountered in metal-forming and high-speed impact applications. This technique is used to maintain the state of the grid and ensure that it is not destroyed due to large distortion in the calculation process. After the calculation steps, the elements are redistributed to adapt to the new model parameters without being destroyed. This process is repeated while the calculation process until the simulation is finished.

One challenge in modelling friction welding is the analysis and determination of the friction coefficient $\mu$. Some authors argue that this coefficient of friction is a constant or the function of the radii of the components [2, 3]. The authors in [5] suggested that the coefficient of friction is proportional to the pressure that acts on the welding surface and the angular velocity. Although the coefficient of friction continuously changes during the welding cycle, the value $\mu>1$ at the beginning and then proceeds to 0 when the temperature attains the melting point at the surface. For 


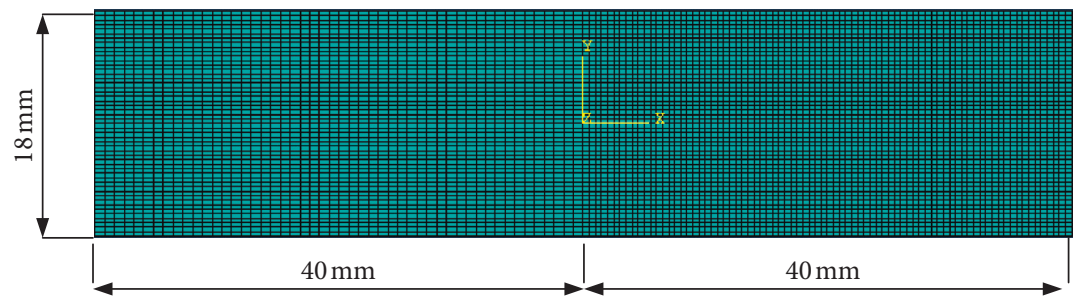

FIGURE 2: 2D model with boundary conditions and meshing arrangement.

simplicity, the coefficient of friction in the welding process is assumed to be constant since the duration of the welding process is short [10].

Modelling the thermal flow during friction welding is a precise description of the heat supplied at the contact surfaces of the welding parts. The torque that is required to create rotational motion for the welded parts under the pressure of axial thrust on the components is determined as [10]

$$
M=\int_{0}^{M_{p}} d M=\int_{0}^{R} \mu P 2 \pi r^{2} d r=\frac{2}{3} \mu \pi P R^{2},
$$

where $M$ is the torque $(\mathrm{N} \cdot \mathrm{m}), \mu$ is the coefficient of friction, $R$ $(\mathrm{mm})$ is the radius of the contact surface, and $P\left(\mathrm{~N} / \mathrm{mm}^{2}\right)$ is the pressure distribution on the contact surface. At the frictional contact surface, the thermal energy per unit area is [3]

$$
\frac{q_{0}}{A}=\frac{1}{A} \int_{0}^{M_{r}} \mu P v d A=\frac{1}{A} \int_{0}^{R} \mu P v_{\max } \frac{r}{R} 2 \pi r d r=\frac{2}{3} \mu P v_{\max },
$$

where $q_{0}$ is the net power (W), $P$ is the pressure, $A$ is the cross-sectional area $\left(\mathrm{mm}^{2}\right), v_{\max }$ is the maximum long velocity at the outermost point $(\mathrm{m} / \mathrm{s})$, and $\mu$ is the coefficient of friction.

Thus, the heat created at the contact surface of two welding parts is a function of the angular velocity and pressure. In this paper, the coefficient of friction is chosen to be constant throughout the modelling, and the value of the friction coefficient is chosen to be $0.577[3,5,8]$.

A part of the heat is transferred from the welding parts to the surrounding air environment by the radiation and convection phenomenon. These two parameters are the convection coefficient and the radiation coefficient, which are detailed in the technical manuals. The initial temperature of the components is determined by a room temperature of $20^{\circ} \mathrm{C}$. The convective heat transfer coefficient between the welded face part and the surrounding environment was chosen to be $100 \mathrm{~W} /\left(\mathrm{m}^{2} \cdot \mathrm{K}\right)[13]$.

The difficulty in simulating friction welding is the high nonlinearity of the material model. Choosing a suitable material model is important for obtaining the accuracy of the simulation results. In this study, the Johnson-Cook material model is used to simulate the rotational friction welding process of titanium alloy. In this model, von Mises's plastic stress varies with the temperature and deformation ratio, as shown in the following formula $[14,15]$ :

$$
\sigma=\left(A+B \varepsilon_{\mathrm{p}}^{n}\right)\left(1+C \ln \dot{\varepsilon}^{*}\right)\left(1+\left(T^{*}\right)^{m}\right),
$$

where $A, B, C, m$, and $n$ are material constants, $\varepsilon_{\mathrm{p}}$ is the degree of plastic deformation, $\dot{\mathcal{\varepsilon}}^{*}$ is the plastic deformation ratio, and $T^{*}$ is the temperature parameter, which is determined as

$$
T^{*}= \begin{cases}0, & T_{\mathrm{r}}<T_{\mathrm{m}}, \\ \frac{\left(T-T_{\mathrm{r}}\right)}{\left(T_{\mathrm{m}}-T_{\mathrm{r}}\right)}, & T_{\mathrm{r}} \leq T \leq T_{\mathrm{m}}, \\ 1, & T>T_{\mathrm{m}},\end{cases}
$$

where $T_{\mathrm{m}}$ is the melting temperature of the material and $T_{\mathrm{r}}$ is the temperature of the environment. In this simulation, the melting temperature of $\mathrm{Ti} 6 \mathrm{Al} 4 \mathrm{~V}$ titanium alloy material was chosen to simulate $1680^{\circ} \mathrm{C}$ [16]. The parameters of the model are presented in Table 1 .

The thermal properties of the material such as the thermal conductivity and the specific heat are changed with variation of the temperature. For titanium alloys, these relationships are shown in Figure 3.

\section{Simulation and Experimental Results}

3.1. Thermal Results and Discussion. Figure 4 illustrates the temperature profile in the workpiece during the rotary friction welding process, assuming the generated power density of $5.3 \mathrm{~W} / \mathrm{mm}^{2}$. The pressure applied in the first stage is $200 \mathrm{MPa}$, and the pressure applied in the second stage is $350 \mathrm{MPa}$. The times for the heating stage and the forging stage are $5 \mathrm{~s}$ and $2.5 \mathrm{~s}$, respectively. For this flux, a temperature of $1633^{\circ} \mathrm{C}$ is attained in approximately 5 seconds at the interface surface and it is reduced to $1457^{\circ} \mathrm{C}$ at the moment of the end process.

The thermal histories of regions near the weld line are interesting since these histories will control the microstructure and the mechanical properties. Figure 5 shows the predicted temperatures during rotary welding process of titanium alloy Ti6Al4V. The specific power is $5.3 \mathrm{~W} / \mathrm{mm}^{2}$ for the heating stage; after $5 \mathrm{~s}$, the temperature at the welding interface is attained at $1633^{\circ} \mathrm{C}$. The region near the welding interface, for example, at the point $z=0.8 \mathrm{~mm}$, attains the highest temperature at the end of the heating stage, while the highest temperature appears during the cooling stage in the region further from the weld line, for example, at the points $z=3.2 \mathrm{~mm}, z=4 \mathrm{~mm}, z=4.8 \mathrm{~mm}$, and $z=5.6 \mathrm{~mm}$, due to the heat transferred from the zone near the weld line with the higher temperature. 
TABLE 1: Parameters of Johnson-Cook model for Ti6Al4V.

\begin{tabular}{lc}
\hline$A(\mathrm{MPa})$ & 880 \\
$B(\mathrm{MPa})$ & 685 \\
$n$ & 0.47 \\
$C$ & 0.035 \\
$m$ & 1 \\
$T_{\mathrm{r}}\left({ }^{\circ} \mathrm{C}\right)$ & 20 \\
$T_{\mathrm{m}}\left({ }^{\circ} \mathrm{C}\right)$ & 1680 \\
$\dot{\varepsilon}$ & 1 \\
\hline
\end{tabular}

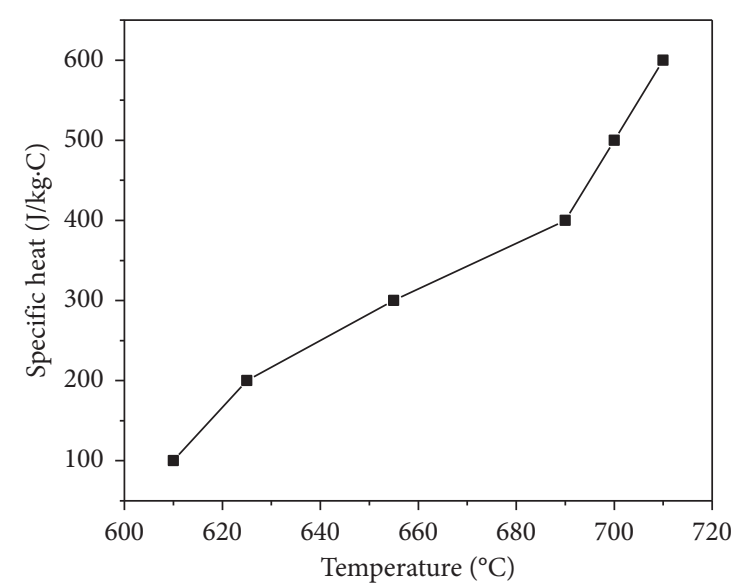

(a)

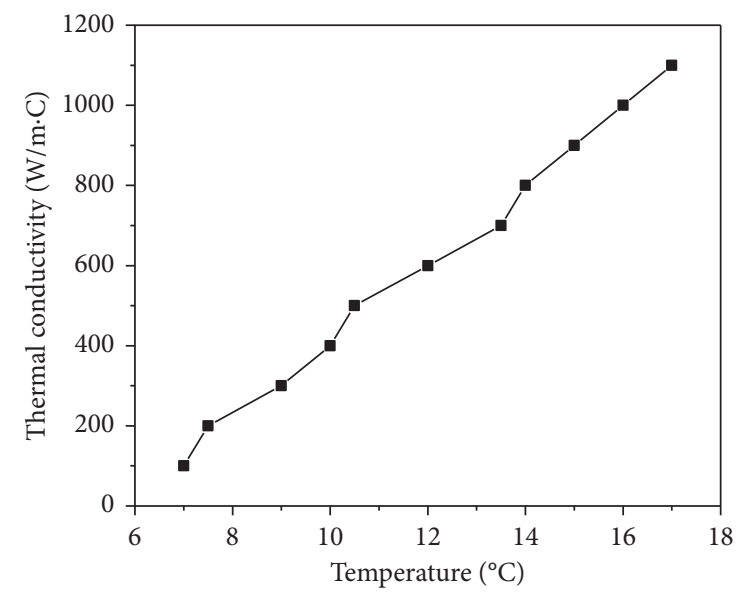

(b)

FIGURE 3: Variation of specific heat and thermal conductivity with temperature.

3.2. Upset Results and Discussion. A general correlation between the upset and the properties is observed; at low upset levels, a lower consistency is observed and some low properties will be encountered. These tensile properties do not appreciably change with an increase in the upset at higher levels [17]. Upset is primarily determined by the total energy input to the weld and the forging pressure. However, the upset is also dependent on the balance between the parameters, e.g., high speed and low speed will yield a different upset from the inverse combination even though the energy is equivalent.

The results of the upset estimated with different forging pressures are presented in Figure 6. The simulation results

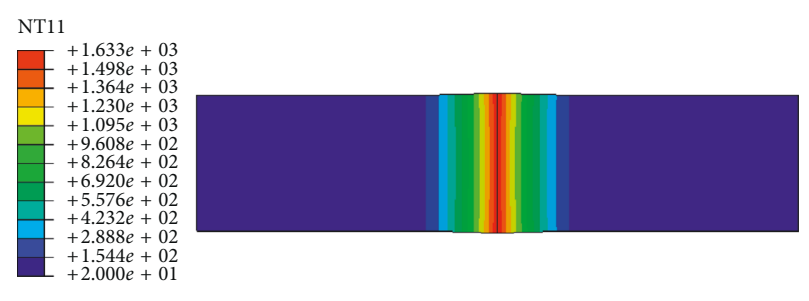

(a)

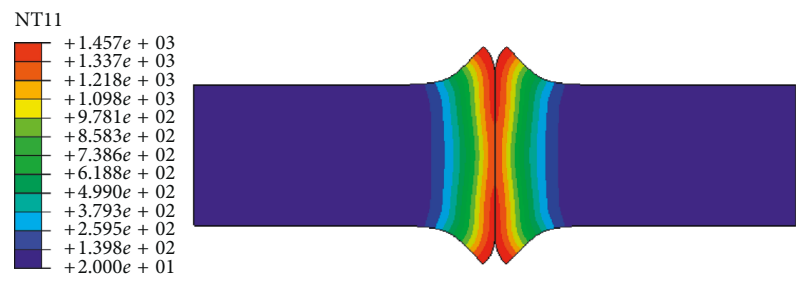

(b)

FIgURE 4: Distribution of temperature at (a) $5 \mathrm{~s}$ and (b) $7.5 \mathrm{~s}$.

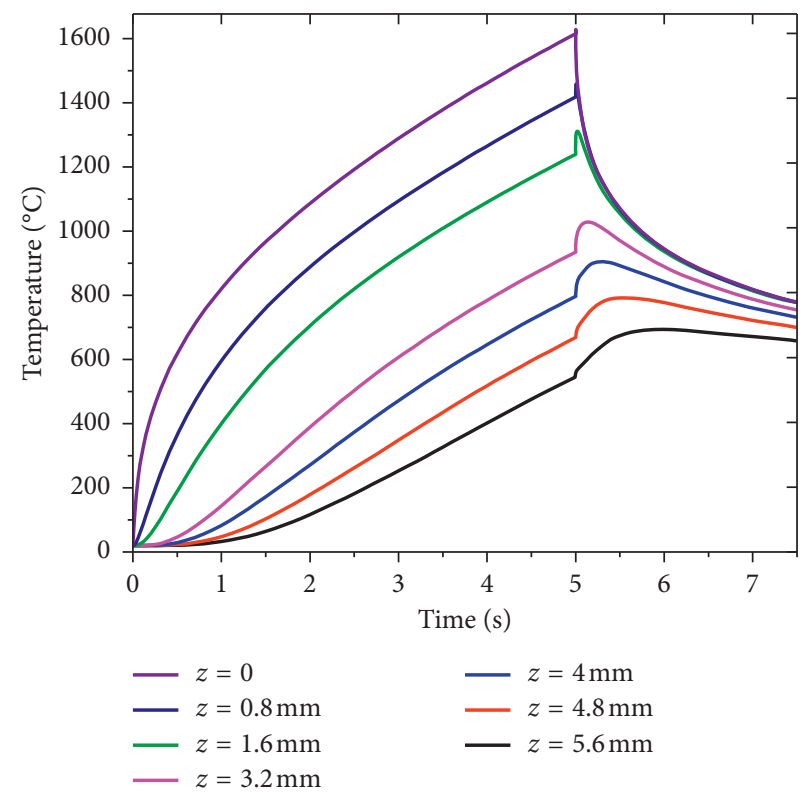

Figure 5: Predicted temperatures during the welding process.

show that the values of the upset substantially decrease from $9.35 \mathrm{~mm}$ to $4 \mathrm{~mm}$ when the forging pressure decreases from $370 \mathrm{MPa}$ to $280 \mathrm{MPa}$. The simulation results also show that the duration of the forging period has minimal effect on the upset. The upset is almost unchanged throughout this period.

Figure 7 presents the experimental results of titanium alloy Ti6Al4V friction welding with a generated power density of $4.3 \mathrm{~W} / \mathrm{mm}^{2}$. When the forging pressure exceeds $350 \mathrm{MPa}$, the upset is excessive. A sound weld zone of forging pressure is observed in the range of $270 \mathrm{MPa}$ to $350 \mathrm{MPa}$.

The temperature at the weld interface varies with the specific weld energy. The simulation results in Figure 8 indicate that the temperatures at the weld interface are $1633^{\circ} \mathrm{C}, 1544^{\circ} \mathrm{C}, 1419^{\circ} \mathrm{C}$, and $1350^{\circ} \mathrm{C}$ with a friction time of 

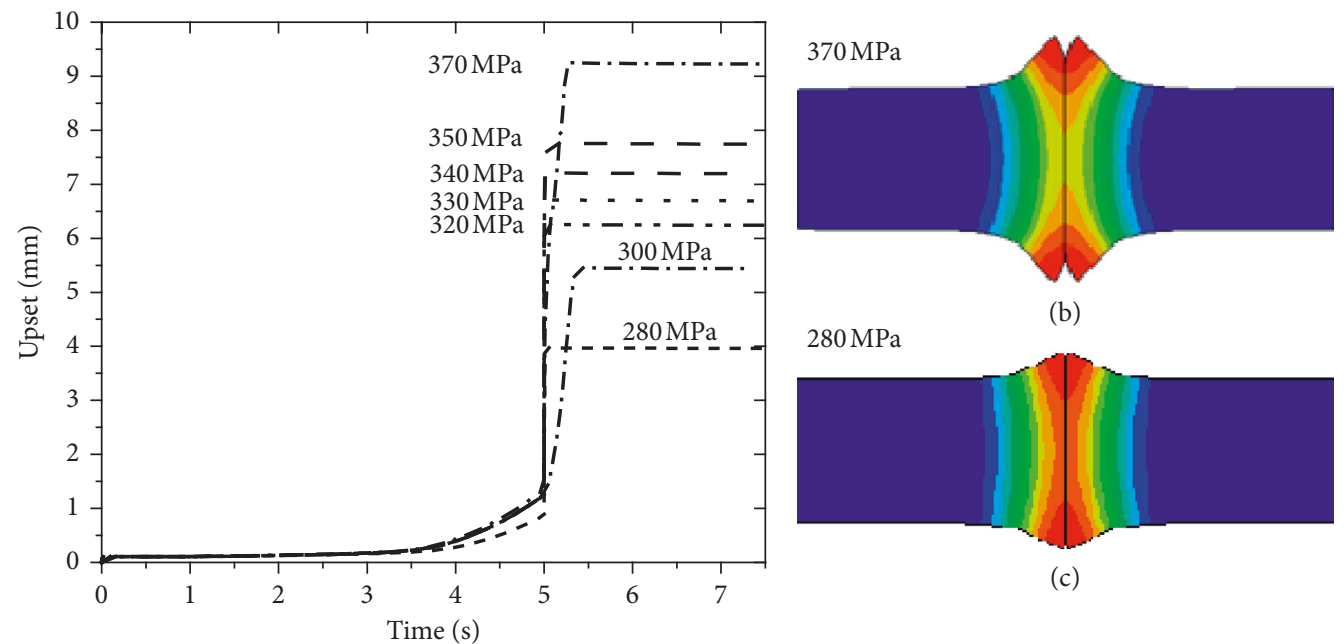

(b)

$280 \mathrm{MPa}$

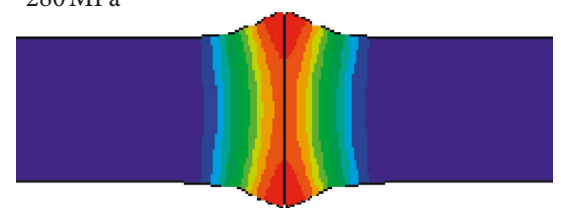

(c)

(a)

FIGURE 6: Simulation results of influence of the forging pressure on the upset of $\emptyset 18 \mathrm{~mm}$ titanium alloys lap with a net power of $5.3 \mathrm{~W} / \mathrm{mm}^{2}$.

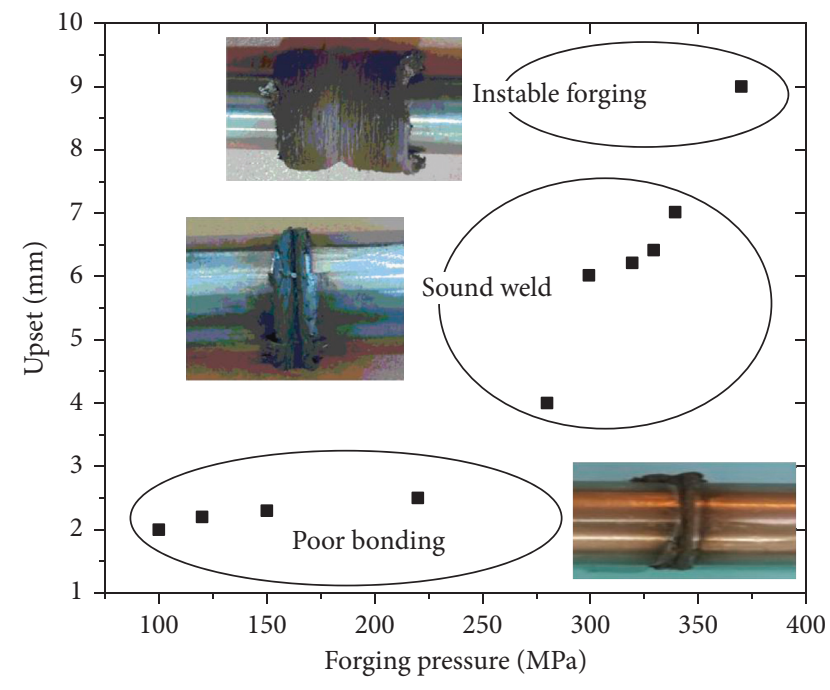

Figure 7: Influence of the forging pressure on the upset.

$5 \mathrm{~s}$ when the generated power density is $5.3 \mathrm{~W} / \mathrm{mm}^{2}, 5.2 \mathrm{~W} /$ $\mathrm{mm}^{2}, 5.0 \mathrm{~W} / \mathrm{mm}^{2}$, and $4.8 \mathrm{~W} / \mathrm{mm}^{2}$, respectively. In these simulations, the forging pressure is kept constant at $340 \mathrm{MPa}$. The upset tends to increase as the generated power density increases.

Figure 9 presents the experimental results with different generated power densities. The low specific weld energy yielded small upsets, while very high specific weld energies caused large upsets. In some cases, the generated power density exceeds $4.6 \mathrm{~W} / \mathrm{mm}^{2}$ and the process became unstable due to excessive plastic deformation. A sound weld zone of the generated power density is observed in the range of $3.8 \mathrm{~W} / \mathrm{mm}^{2}$ to $4.3 \mathrm{~W} / \mathrm{mm}^{2}$.

The two parameters that affect the upset during rotary friction welding are the generated power density and the forging pressure. However, equation (2) shows that the generated power density depends on the rotational speed and friction pressure. Therefore, the process of friction welding enables a larger variation of welding parameters to produce

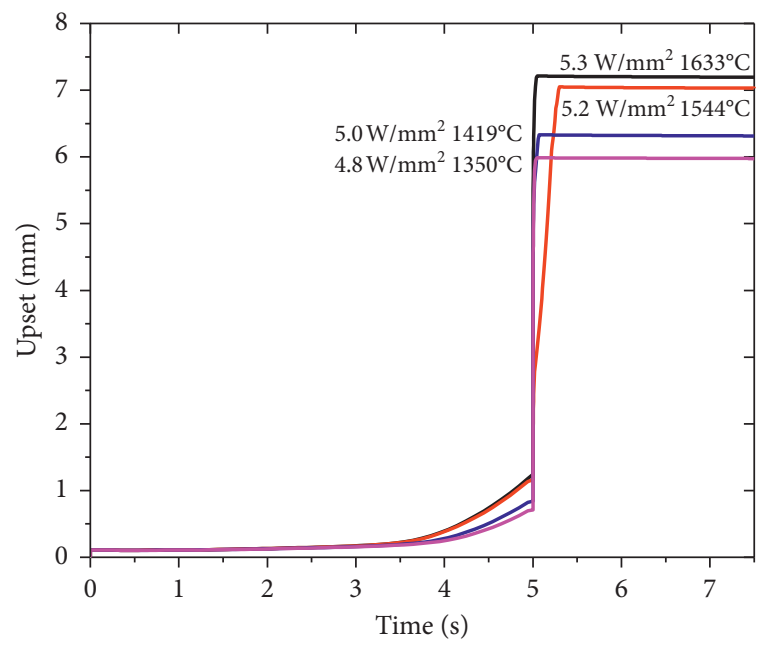

FIGURE 8: Simulation results of influence of the specific weld energy on the upset of $\varnothing 18 \mathrm{~mm}$ titanium alloys lap with a forging pressure of $340 \mathrm{MPa}$.

satisfactory bonding welds. The friction pressure, forging pressure, friction time, and spindle deceleration were varied. The forging time has a minimal effect on the upset.

3.3. Microstructure. Figure 10 shows the experimental setup that was employed to observe the microstructure and to measure the hardness of the friction welded joints in this study. A rotary friction welded titanium alloy Ti6Al4V joint with a generated power density of $4.3 \mathrm{~W} / \mathrm{mm}^{2}$ and a forging pressure of $270 \mathrm{MPa}$ is shown in Figure 11. The experimental results show that the weld joints are continuous. The joint has an excellent surface appearance without any oxidization colour.

As shown in Figure 11, the weld exhibits a shape that is typically observed within rotary friction welding, and the width at the edge of the weld interface is almost twice the width at the centre. 


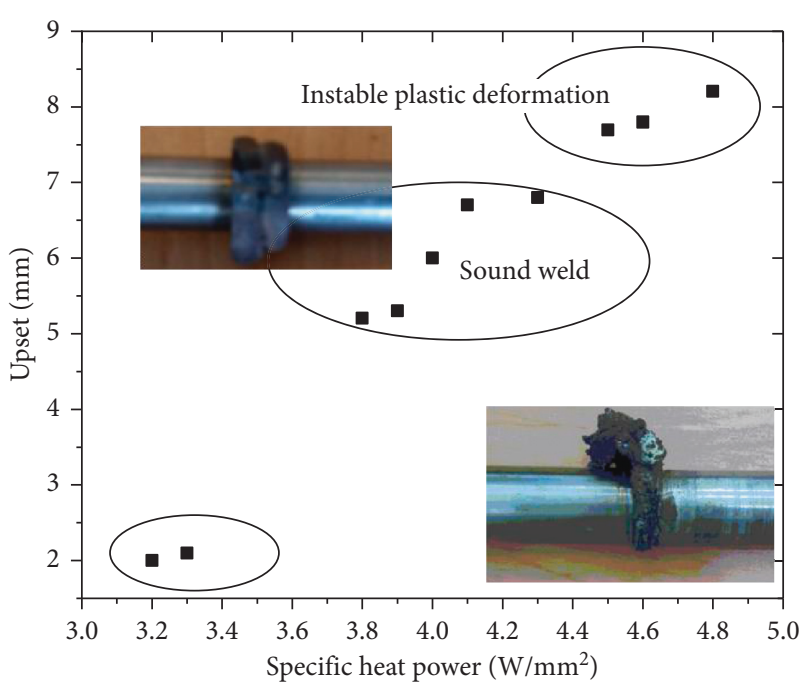

FIGURE 9: Influence of the generated power density on the upset.
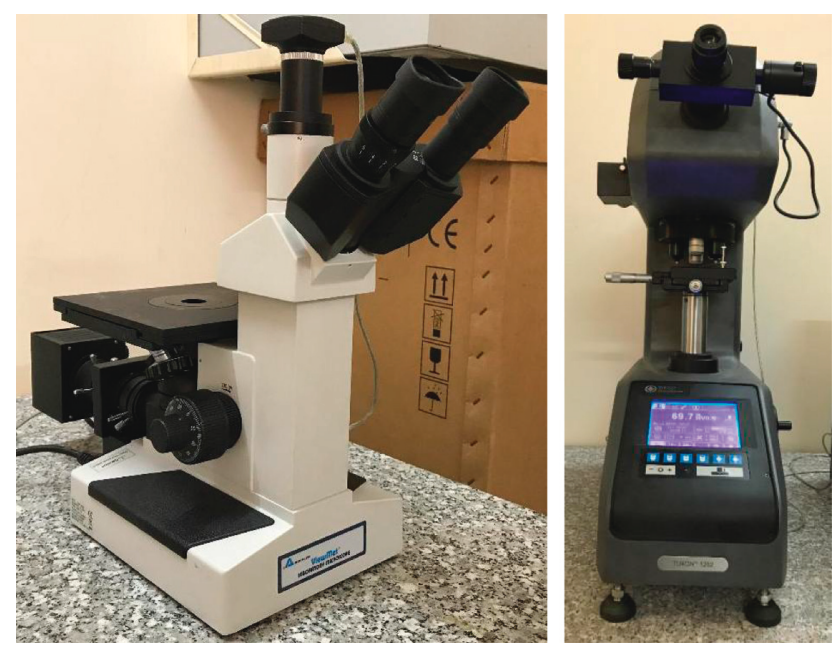

Figure 10: Experimental apparatus.

3.3.1. Base Metal (BM). The microstructure of the Ti6AlV4 base material (adjacent to the heat-affected zone) consists of an initial microstructure that is characterized by the elongated primary $\alpha$ and the transformed $\beta$, as shown in Figure 12.

3.3.2. Heat-Affected Zone (HAZ). The heat-affected zone (HAZ) is very thin. However, a distinction is observed between the microconstructs that are developed near the interface in the two joined parts. The narrow HAZ is related with the small thermoconductivity of the Ti6Al4V titanium alloy. Figure 13 shows the material microstructure of the heat-affected zone. In the area of the heat-affected zone, the $\alpha$ mixed crystals dissolve and the microstructure, which consists of pure, nodular $\alpha$, may be accompanied by low $\beta$ portions. As shown in Figures 12 and 13, the microstructure of the HAZ is similar to that of the BM with an increase in the volume fraction of $\beta$. The increase in $\beta$ in the HAZ can be explained by the annealing effect due to the friction heat

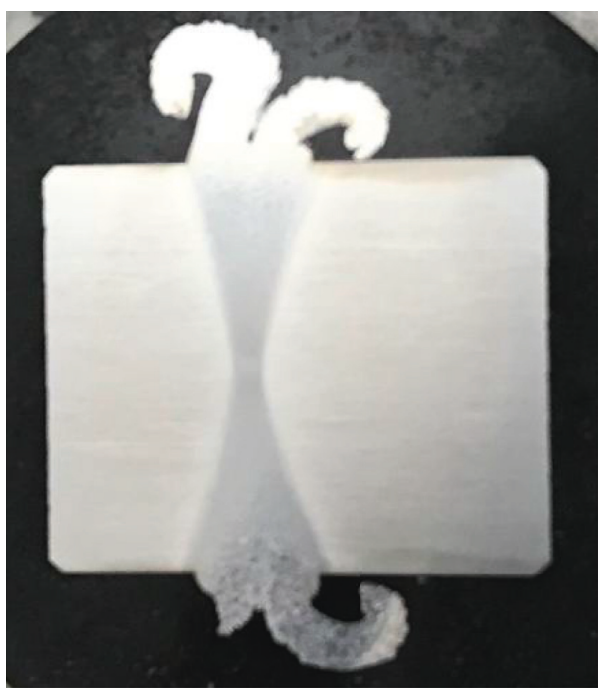

FIgURE 11: Typical microstructure of a rotary friction weld in Ti6Al4V.

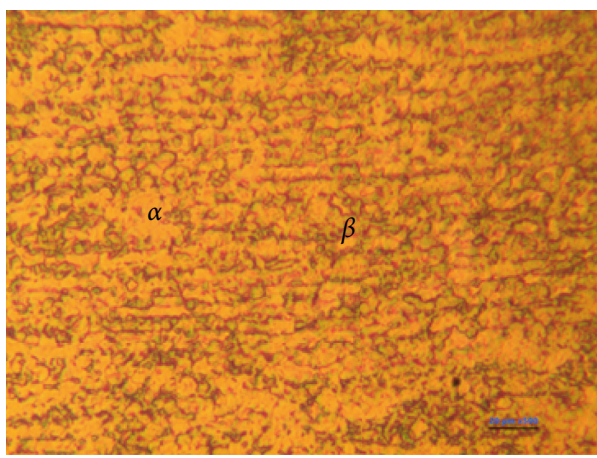

FIGURE 12: Microstructures of BM.

during RFW. The temperature in the HAZ is below the $\beta$-transus temperature but above the $\beta \longrightarrow \alpha+\beta$ transformation temperature. Thus, the $\alpha \longrightarrow \beta$ transformation can occur in this region in the heating stage of the RFW process, which generates an increase in the volume fraction of $\beta$. However, the high-temperature residence time in the HAZ is relatively short; thus, the increase in the volume fraction of $\beta$ is not significant.

In the HAZ, a material flow is observed in the hoop direction. This flow is attributed to the nature of the rotary friction welding process, and the material flow in a circular motion is consistent with the rotating component against the stationary component. This material flow was not observed in the radial direction, however, and has never been observed.

3.3.3. Welding Zone (WZ). The material in the welding zone attains high temperatures and experiences high strains during RFW. The material works at temperatures that are sufficiently high to induce recrystallization. The welding zone only consists of the equiaxed primary $\alpha$ and the transformed $\beta$ in this study, as shown in Figure 14. Compared with the base metal, the microstructure in the welding zone is significantly refined. 


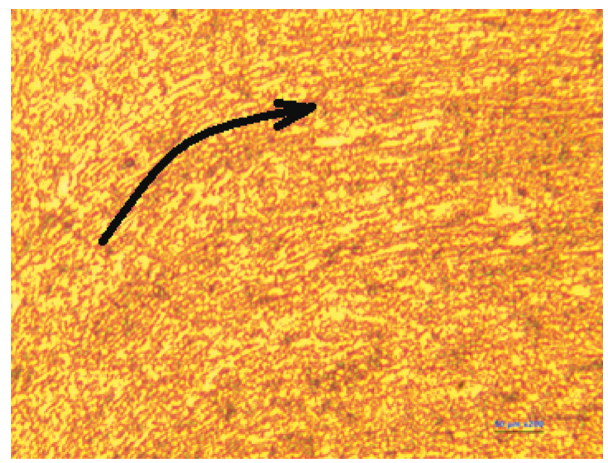

Figure 13: Microstructures of HAZ.

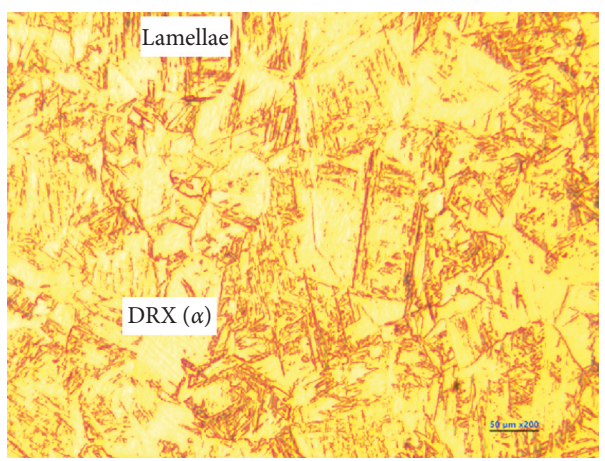

Figure 14: Microstructures of WZ.

Large amounts of equiaxed primary $\alpha$ grains with dislocation densities are formed in the welding zone. Dynamic recrystallization (DRX) has occurred in the welding zone due to significant plastic deformation and frictional heating during RFW.

Transformed $\beta$ in the welding zone is characterized by a fine lamellar $(\alpha+\beta)$ microstructure, and the microstructure in the welding zone can be defined as a bimodal microstructure. The formation of a bimodal microstructure in the welding suggests that the peak temperature is below the $\beta$-transus temperature, and primary $\alpha$ recrystallization, which is known as $\alpha$ globularization, proceeds in the welding zone during the heating stage of the welding process. The $\beta \longrightarrow \alpha+\beta$ transformation is produced in the cooling stage of the RFW process, which produces a fine alternate lamellar $\alpha+\beta$ microstructure due to a relatively high cooling rate. Therefore, a bimodal microstructure is developed in the welding.

The gradual change in the microstructure from the weld interface to the parent material is clearly depicted at high resolution in Figure 15.

Figure 16 shows two welding patterns with forging pressures of $370 \mathrm{MPa}$ and $270 \mathrm{MPa}$, respectively. The experimental results show that when the forging pressure is excessive, the width of the welding zone becomes very small.

3.4. Vickers Hardness. To explain the tensile characteristics of the welded joint, the Vickers hardness distribution of the welded joint was measured, as shown in Figure 17. Compared with the hardness of the base material of $330-340 \mathrm{HV}$, the hardness around the joint area is increased in a small area to $\pm 1.5 \mathrm{~mm}$. This hardness increase is due to the strengthening caused by the upset procedure. The higher hardness increase to $360 \mathrm{HV}$ is obtained in the connection. The hardness profile shows no significant differences between the two welding specimens.

Although the hardness of the two welded specimen is nearly the same, the welded specimen with a forging pressure of $270 \mathrm{MPa}$ is better as the length of the parts is shorter than that of the parts with a forging pressure of $370 \mathrm{MPa}$.

\section{Conclusions}

Rotary friction welding for Ti6Al4V titanium alloy has been investigated by numerical analysis and experiments. Titanium alloy Ti6Al4V similar metal joints were successfully welded by the rotary friction welding process. The titanium rotary friction welds achieve a tensile strength that is higher than that of the base material.

An increase in the forging pressure produces an increased upset. Therefore, a small forging pressure is preferred in the friction welding process. Upset thresholds were determined between $5 \mathrm{~mm}$ and $7 \mathrm{~mm}$ for small-size specimens of Ti6Al4V. Below $5 \mathrm{~mm}$, insufficient bonding was observed, whereas the welding process became unstable above $7 \mathrm{~mm}$.

During the initial friction stage, the temperature at the friction interface rapidly increases, while the temperature becomes uniform and almost constant during the steady friction stage. The RFW of Ti6Al4V titanium alloy consists of the WZ, HAZ, and BM. The microstructure of the HAZ is 


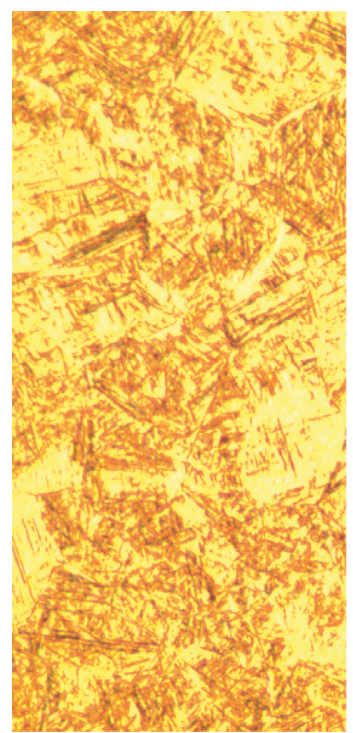

WZ

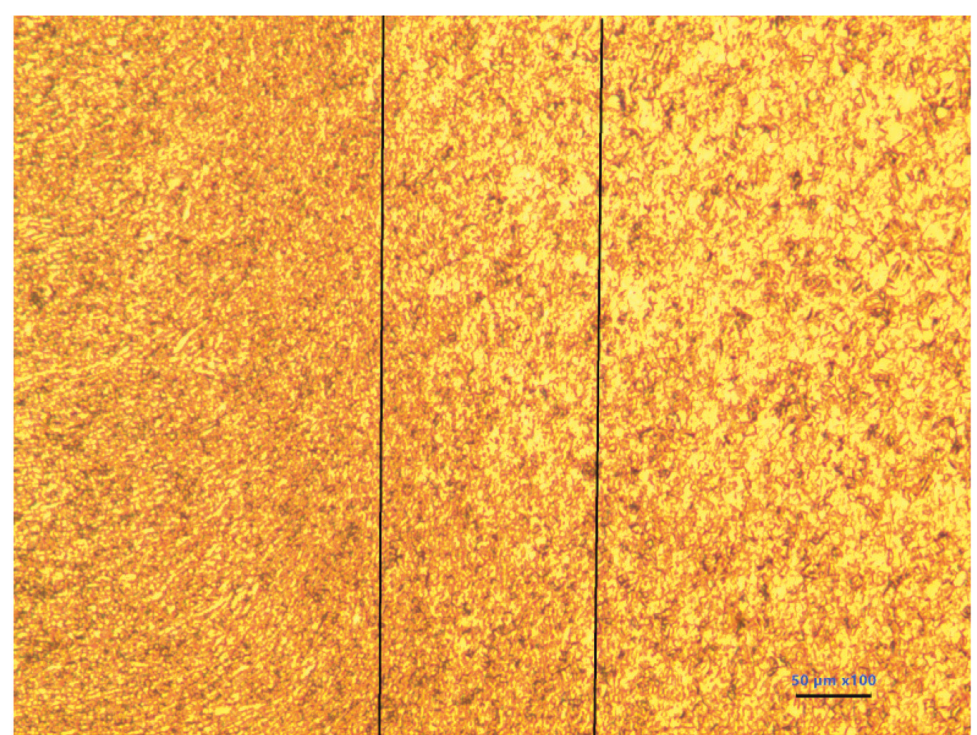

HAZ

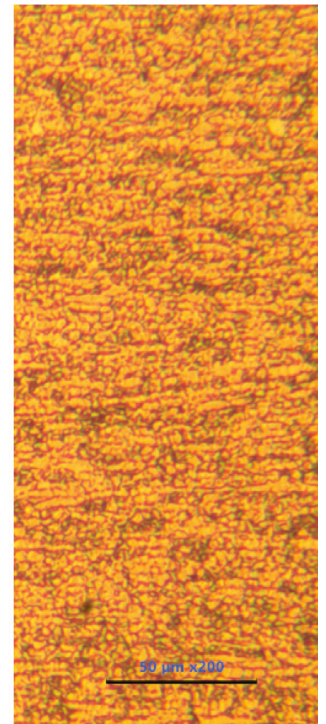

$\mathrm{BM}$

FIGURE 15: Change in the microstructure in the welding region of rotary welding of Ti6Al4V.

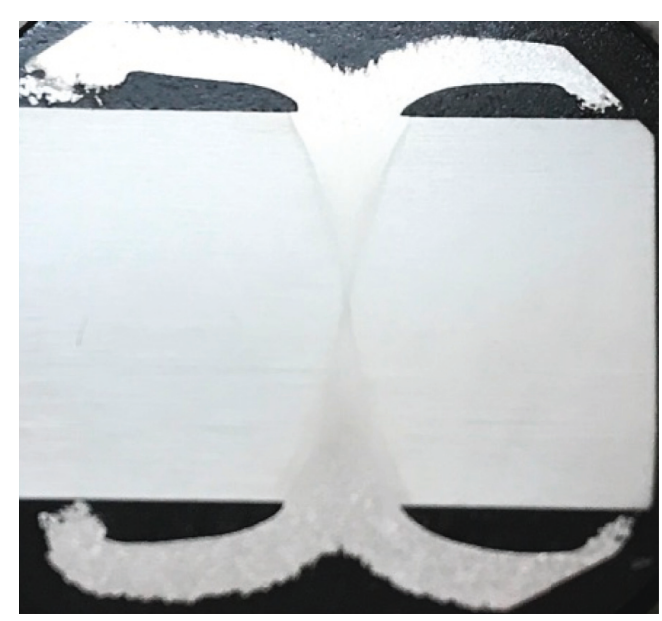

(a)

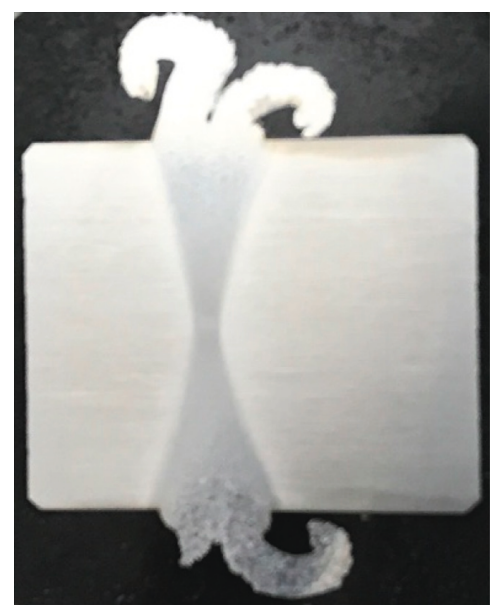

(b)

FIgURE 16: Different welding cross sections with generated power density of $4.3 \mathrm{~W} / \mathrm{mm}^{2}$. (a) Forging pressure of $370 \mathrm{MPa}$. (b) Forging pressure of $270 \mathrm{MPa}$.

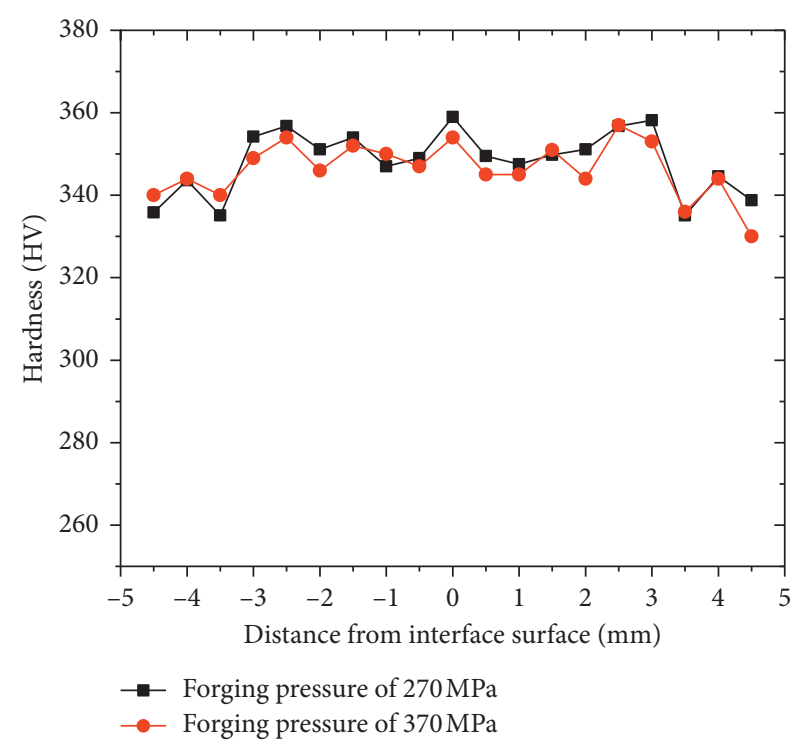

Figure 17: Vickers hardness distribution in welding section.

similar to that of the BM with an increase in the volume fraction of $\beta$. The $\mathrm{WZ}$ is characterized by dynamically recrystallized $\alpha$ grains and transformed $\beta$ with a fine $\alpha+\beta$ lamellar microstructure.

The study proves the viability of rotary friction welding as a possible means of joining Ti6Al4V.

\section{Data Availability}

The data used to support the findings of this study are available from the corresponding author upon request.

\section{Conflicts of Interest}

The authors declare that there are no conflicts of interest regarding the publication of this paper. 


\section{Acknowledgments}

This research is funded by Ho Chi Minh City University of Technology, VNU-HCM, under grant number BK-SDH2019-8140019.

\section{References}

[1] B. Flipo, K. Beamish, B. Humphreys, and M. Wood, "Linear friction welding of Ti6Al4V for aerostructure applications," in Proceedings of the 10th International Conference on Trends in Welding Research, Tokyo, Japan, October 2016.

[2] M. B. Uday, M. N. Ahmad Fauzi, H. Zuhailawati, and A. B. Ismail, "Advances in friction welding process: a review," Science and Technology of Welding and Joining, vol. 15, no. 7, pp. 534-558, 2010.

[3] A. Chamanfar, M. Jahazi, and J. Cormier, "A review on inertia and linear friction welding of Ni-based superalloys," Metallurgical and Materials Transactions A, vol. 46, no. 4, pp. 1639-1669, 2015.

[4] I. Bhamji, M. Preuss, P. L. Threadgill, R. J. Moat, A. C. Addison, and M. J. Peel, "Linear friction welding of AISI 316L stainless steel," Materials Science and Engineering: A, vol. 528, no. 2, pp. 680-690, 2010.

[5] A. R. McAndrew, P. A. Colegrove, A. C. Addison, B. C. D. Flipo, M. J. Russell, and L. A. Lee, "Modelling of the workpiece geometry effects on Ti-6Al-4V linear friction welds," Materials \& Design, vol. 87, pp. 1087-1099, 2015.

[6] W. Li, A. Vairis, M. Preuss, and T. Ma, "Linear and rotary friction welding review," International Materials Reviews, vol. 61, no. 2, pp. 71-100, 2016.

[7] T. J. Ma, B. Zhong, W.-Y. Li, Y. Zhang, S. Q. Yang, and C. L. Yang, "On microstructure and mechanical properties of linear friction welded dissimilar Ti-6Al-4V and Ti-6.5Al3.5Mo-1.5Zr-0.3Si joint," Science and Technology of Welding and Joining, vol. 17, no. 1, pp. 9-12, 2012.

[8] M. R. Daymond and N. W. Bonner, "Measurement of strain in a titanium linear friction weld by neutron diffraction," Physica B: Condensed Matter, vol. 325, pp. 130-137, 2003.

[9] E. C. Dalgaard, "Evolution of microstructure, micro-texture and mechanical properties in linear friction welded titanium alloys," Canadian Journal of Metallurgy and Materials Science, vol. 51, no. 2, pp. 269-276, 2012.

[10] M. Avinash, G. V. K. Chaitanya, D. K. Giri, S. Upadhya, and B. K. Muralidhara, "Microstructure and mechanical behaviuor of rotary friction welded titanium alloys," International Journal of Materials and Metallurgical Engineering, vol. 1, no. 11, pp. 641-643, 2007.

[11] R. Palanivel, R. F. Laubscher, I. Dinaharan, and D. G. Hattingh, "Microstructure and mechanical characterization of continuous drive friction welded grade 2 seamless titanium tubes at different rotational speeds," International Journal of Pressure Vessels and Piping, vol. 154, pp. 17-28, 2017.

[12] A. Yates, "The effect of microstructure on mechanical properties in inertia welded titanium 6-4," Master thesis, University of Birmingham, Birmingham, UK, 2015.

[13] O. T. Midling and $\varnothing$. Grong, "A process model for friction welding of $\mathrm{Al}-\mathrm{Mg}-\mathrm{Si}$ alloys and $\mathrm{Al}-\mathrm{SiC}$ metal matrix composites-I. Haz temperature and strain rate distribution," Acta Metallurgica et Materialia, vol. 42, no. 5, pp. 1595-1609, 1994.

[14] F. Schroeder, R. M. Ward, R. P. Turner, M. M. Attallah, J. Gebelin, and R. C. Reed, "Linear friction welding of titanium alloys for aeroengine applications: modelling and validation," in Proceedings of 9th International Conference on Trends in Welding Research, pp. 886-892, Chicago, IL, USA, June 2012.

[15] G. Chen, C. Ren, X. Qin, and J. Li, “Temperature dependent work hardening in Ti-6Al-4V alloy over large temperature and strain rate ranges: experiments and constitutive modeling," Materials \& Design, vol. 83, pp. 598-610, 2015.

[16] G. R. Johnson and W. H. Cook, "A constitutive model and data for metals subjected to large strains, high strain rates and high temperatures," in Proceedings of the 7th International Symposium on Ballistics, pp. 541-547, The Hague, Netherlands, April 1983.

[17] C. G. Nessler, D. A. Rutz, R. D. Eng, and P. A. Vozzella, "Friction welding of titanium alloys," Welding Journal, vol. 50, no. 9, pp. 379-345, 1971. 


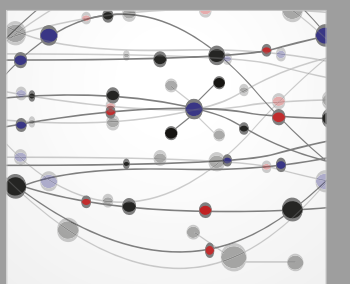

The Scientific World Journal
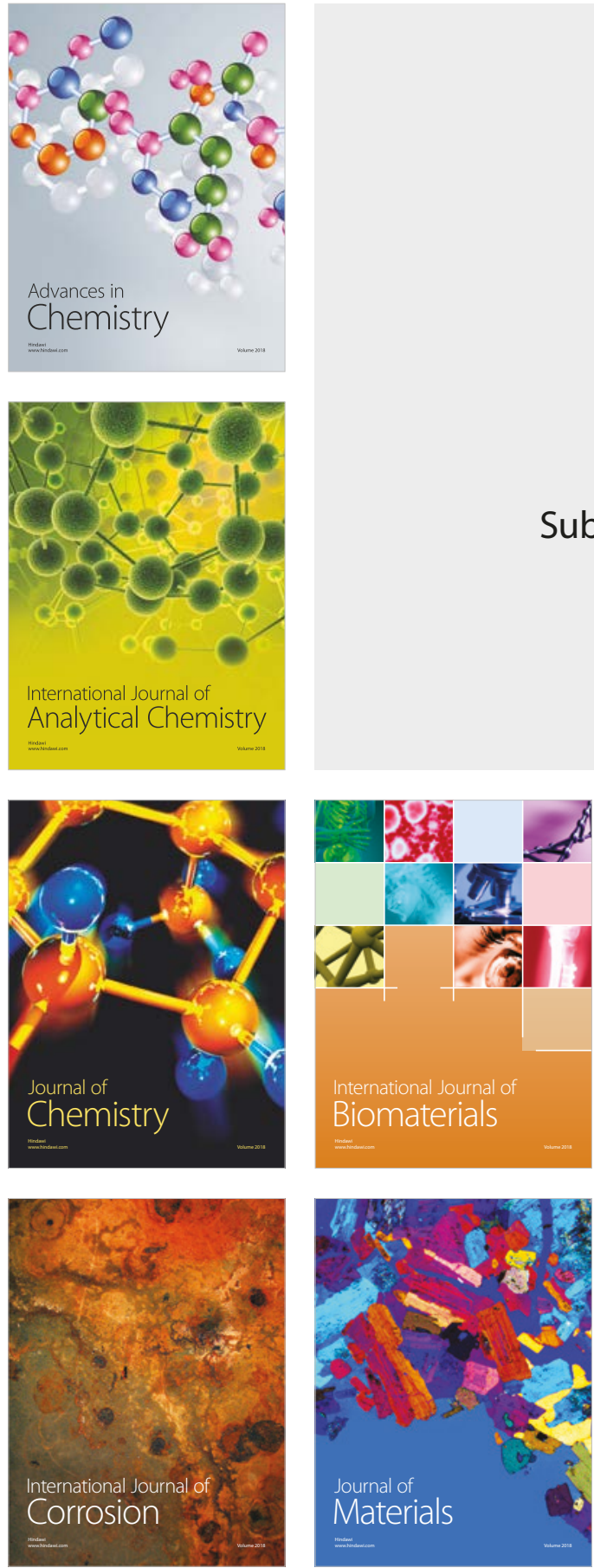

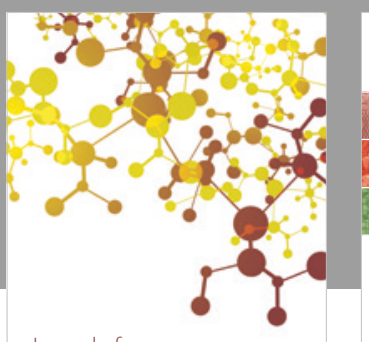

Journal of

Applied Chemistry
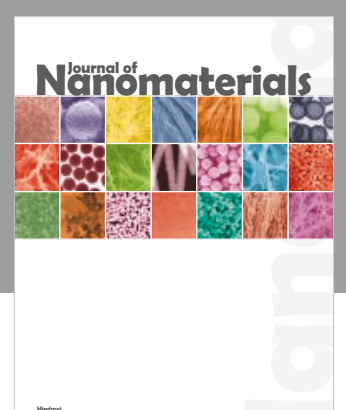

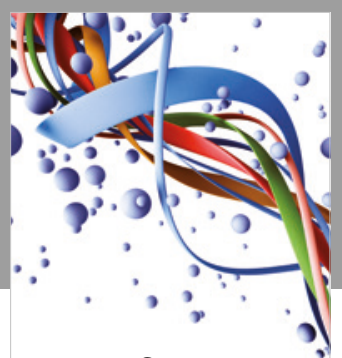

Scientifica

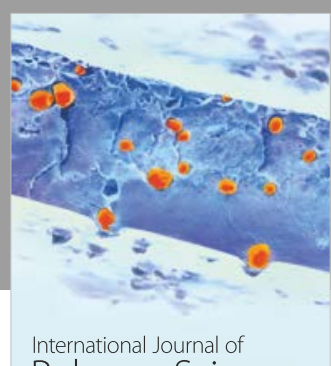

Polymer Science

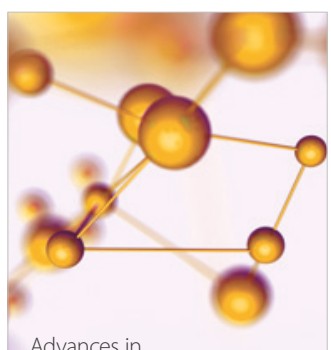

Physical Chemistry
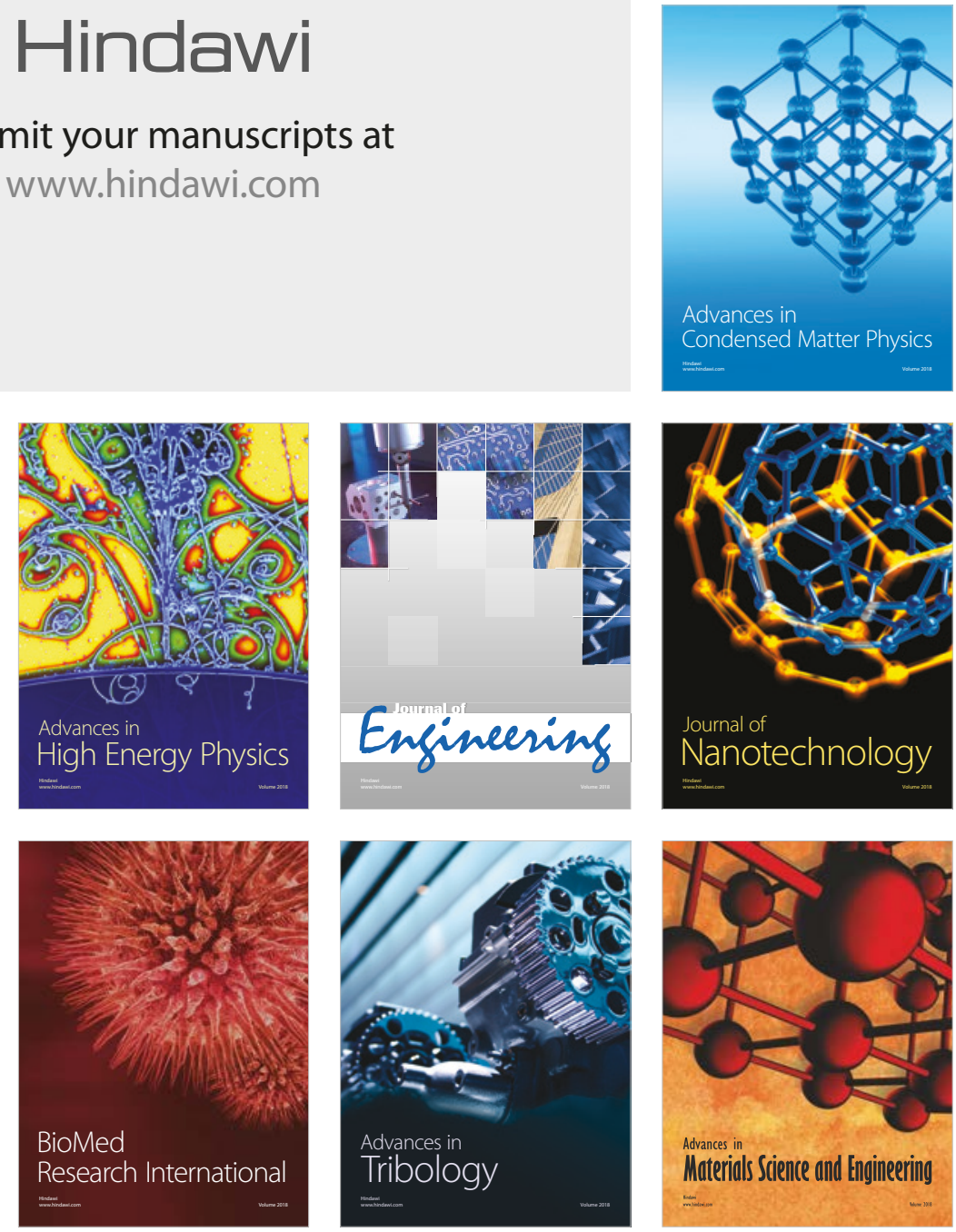